\section{Endoscopic sphincterotomy for common bile duct calculi}

SIR, - Davidson et al have clearly shown that endoscopic sphincterotomy (ES) is an effective method in the management of common bile duct calculi also in patients with gall bladder in situ. ${ }^{1}$ Their study showed that the only factor of value in predicting biliary complications was pre-existing cholangitis. This interpretation, however, may cause misunderstanding because the possibility of cholangitis must be taken into consideration in all cases with bile duct stones.

Our experience indicates that, if anything, it is the presence of gall bladder stones which has predictive value for biliary complication in patients with gall bladder in situ ${ }^{2}$.

Of 1223 endoscopic sphincterotomies, we carried out $318(26 \%)$ examinations in patients with gall bladder present. In this series the indications were bile duct stones in 176 patients with and in 47 cases without stones in the gall bladder. Early complications occurred in 18 patients $(8 \%)$, of these 10 developed cholangitis and cholecystitis. All patients with cholangitis had stones not only in the bile ducts but also in the gall bladder.

We have follow up results from 159 patients for six months to eight years (mean 5.2 years). Of these patients 43 had biliary symptoms during the follow up period. In 22 patients recurrence of common bile duct stones could be observed, while in eight cases the stenosis of the papilla of Vater was detected.

Twenty three patients developed acute cholecystitis during the follow up; all had stones in the gall bladder. None of the patients with gall bladder in situ without stones developed biliary inflammation.

Both the early complications and the longterm outcome of endoscopic sphincterotomies in our series indicate that the presence of gall bladder stones is of significant value in predicting biliary complications after ES.

In contrast with Davidson's data our results show that the risk of biliary complications is increased in patients with stones in the gall bladder compared with those with gall bladder in situ without stones.

First Dept of Medicine,

Z TULASSAY AND J PAPP

Semmelweis University,

Medical School,

Budapest, Hungary

\section{References}

1 Davidson BR, Neoptolemos JP, Carr-Locke DL. Endoscopic sphincterotomy for common bile duct calculi in patients with gall bladder in situ considered unfit for surgery. Gut 1988; 29: 114-20.
2 Tulassay Z, Papp J. Complications of endoscopic sphincterotomy in patients with intact gallbladder. Gastrointest Endosc 1985; 31: 111-2.

\section{Reply}

SIR, - We are grateful for the learned comments of Drs Tulassay and Papp. They indicate that in their extensive experience gall bladder complications after ES only occurred in patients with gall stones still present. Although they suggest this experience contrasts with ours, this difference is more apparent than real.

Their incidence of gall bladder complications, 23/ 159 patients or $14.5 \%$ is similar to ours which was $12 / 98$ patients or $12.5 \%$. Eleven of our 12 patients who developed gall bladder complications had either gall stones still present or a blocked cystic duct (nonfilling of the gall bladder by contrast), implying the presence of gall bladder stones. The incidence of no gall bladder stones in the Leicester study was only eight of 98 patients or $8.2 \%$ - perchance accounting for the lack of statistical significance. In contrast this was $47 / 223$ patients or $21.1 \%$ in the Semmelweis series. It is perhaps noteworthy that the Leicester follow up rate was $100 \%$ compared with $70 \%$ in Semmelweis.

Thus given that the great majority of our patients do have gall stones within the gall bladder it was the presence of factors over and above this that we examined in order to predict an increased risk of gall bladder complications. To this end we could not find any, with the sole exception that empyema of the gall bladder was more commonly associated with preexisting cholangitis. Moreover some patients without gall bladder stones can also develop gall bladder complications. Whereas we have little basis by which to contest the idea that gall bladder complications are commoner in patients with gall stones still present, from a practical point of view all patients do require careful follow-up. This is particularly pertinent in the first few weeks to months after resolution of acute cholangitis as they are more prone to empyema of the gall bladder which may prove to be lethal.

J P NEOPTOLEMOS

Dept of Surgery,

Dudley Road Hospital,

Birmingham B18 $7 Q H$.

\section{Book review}

The liver: biology and pathobiology. Edited by Arias, Jakoby, Popper, Schachter, and Shafritz. (Pp. 1377; illustrated; £244.) New York: Raven Press, 1988. 
This book was written with the aim of bridging the ever increasing gap between basic biology and medicine. Scientists whose work involves fundamental aspects of liver structure and function and clinical investigators whose interest usually relates to disease mechanisms have contributed their knowledge and ideas. The first edition was published in 1982 and it is remarkable that in the six years since then there have been so many major advances, particularly in cellular and molecular biology, immunology and electrophysiology, that a new edition is required.

The book is logically organised into sections starting with the cells; inter-related cell functions follows, then in turn, the organ, including hepatic circulation and hepatic nerve function; relation to other organs, including blood coagulation, the kidney and liver disease, hepatobiliary influences on the skeletal system, hepatic encephalopathy; and pathobiological analysis of disease mechanisms. The latter comprises superb reviews of basic knowledge and clinical interactions in cholestasis, hepatic neoplasia, portal hypertension, and alpha-1-antitrypsin deficiency.

The final section entitled Horizons is a new section of selected areas where major development is expected in the future and covering the idiotype network, magnetic resonance spectroscopy and targetting in diagnosis and therapy.

It would be invidious to pick out individual contributors for they are clearly all outstanding in their specific areas as well as having an interest in the wider knowledge. The volume can only be described by superlatives; the reviewer was thrilled when he saw the book and even more thrilled when he had finished dipping into it for his review. Every real worker on the liver whether in the clinic or the laboratory needs to have this available. The editors in the introduction to the first volume wrote: 'The authors and editors will have achieved their goal if the reader finds in these pages exciting glimpses into the current state and future directions of our discipline . . . An ambitious goal that has been achieved.

ROGER WILLIAMS

\section{News}

4th South-East-European Symposium on Paediatric Surgery

This symposium on 'Normal and Disturbed Esophageal function in Childhood' will be held in Graz, Austria, on 8-9 September, 1989. Details from: Professor Dr H Sauer, Dept of Paediatric Surgery, University of Graz, Heinrichstrasse 31, A-8010 Graz, Austria.

\section{Sir Francis Avery Jones BSG Research Award 1989}

A three page summary of personal research work is invited by the Education Committee of the British Society of Gastroenterology who will recommend to Council the recipient of the 1989 Award. A bibliography may also be submitted if desired. The Award consists of a medal and $£ 100$ prize. Entrants must be 40 years or less on 31 December 1989 but need not be a member of the BSG. All (or a substantial part) of the work must have been done in the UK or Eire. The recipient will be required to deliver a 40 minute lecture at the Plenary Session of the Spring meeting of the Society in Bradford in 1989. Applications (15 COPIES) should be made to: The Honorary Secretary, BSG, 3 St Andrew's Place, Regent's Park, London, NW1 4LB, by 1 December 1988.

American Association for the Study of Liver Diseases A postgraduate course on 'Current Hepatology - an Update on Science and Practice' will be held in Chicago, Illinois, USA, on 5-6 November, 1988, followed by the 39th Annual Meeting of the American Association for the Study of Liver Diseases on 7-8 November, 1988. Details from: Registration Supervisor, SLACK Inc, 6900 Grove Road, Thorofare, NJ 08086-9447, USA.

\section{Course in Gastroenterology: Oxford}

To be held from 3-6 January, 1989, at the John Radcliffe Hospital. Further details from: Dr D P Jewell, Radcliffe Infirmary, Oxford OX2 6HE. Tel: Oxford (0865) 816829. 